\title{
Genomotyping of Pseudomonas putida strains using $P$. putida KT2440-based high-density DNA microarrays: implications for transcriptomics studies
}

\author{
Hendrik Ballerstedt • Rita J. M. Volkers • \\ Astrid E. Mars • John E. Hallsworth • \\ Vitor A. Martins dos Santos • Jaçek Puchalka • \\ Joost van Duuren • Gerrit Eggink • Ken N. Timmis • \\ Jan A. M. de Bont • Jan Wery
}

Received: 7 December 2006 /Revised: 26 February 2007 / Accepted: 27 February 2007 / Published online: 17 March 2007

(C) Springer-Verlag 2007

\begin{abstract}
Pseudomonas putida KT2440 is the only fully sequenced $P$. putida strain. Thus, for transcriptomics and proteomics studies with other $P$. putida strains, the $P$. putida KT2440 genomic database serves as standard reference. The utility of KT2440 whole-genome, high-density oligonucleotide microarrays for transcriptomics studies of other Pseudomonas strains was investigated. To this end, microarray hybridizations were performed with genomic DNAs of subcultures of P. putida KT2440 (DSM6125), the type strain $\left(\mathrm{DSM} 291^{\mathrm{T}}\right)$, plasmid pWW0-containing KT2440-derivative
\end{abstract}

H. Ballerstedt $(\bowtie) \cdot$ R. J. M. Volkers $\cdot$ J. A. M. de Bont $\cdot$ J. Wery TNO Quality of Life,

Business Unit Food and Biotechnology Innovations,

Julianalaan 67 ,

2628 BC Delft, The Netherlands

e-mail: hendrik.ballerstedt@tno.nl

\author{
A. E. Mars · J. van Duuren · G. Eggink \\ Wageningen University and Research Center, \\ Agrotechnology and Food Sciences Group, Biobased Products, \\ Bornsesteeg 59, \\ 6708 PD Wageningen, The Netherlands
}

J. E. Hallsworth

School of Biological Sciences, MBC, Queen's University Belfast, BT9 7BL Belfast, Ireland

V. A. Santos $\cdot$ J. Puchalka $\cdot$ K. N. Timmis

GBF-National Research Centre for Biotechnology,

Mascheroder Weg 1,

38124 Braunschweig, Germany

J. A. M. de Bont

Faculty of Applied Sciences, Delft University of Technology,

P.O. Box 5045, 2600 GA Delft, The Netherlands strain mt-2 (DSM3931), the solvent-tolerant P. putida S12, and several other Pseudomonas strains. Depending on the strain tested, 22 to $99 \%$ of all genetic elements were identified in the genomic DNAs. The efficacy of these microarrays to study cellular function was determined for all strains included in the study. The vast majority of DSM6125 genes encoding proteins of primary metabolism and genes involved in the catabolism of aromatic compounds were identified in the genomic DNA of strain S12: a prerequisite for reliable transcriptomics analyses. The genomotypic comparisons between Pseudomonas strains were used to construct highly discriminative phylogenetic relationships. DSM6125 and DSM3931 were indistinguishable and clustered together with strain S12 in a separate group, distinct from DSM291 ${ }^{\mathrm{T}}$. Pseudomonas monteilii (DSM14164) clustered well with $P$. putida strains.

Keywords Pseudomonas putida . Transcriptomics . Genomotyping $\cdot$ Solvent-tolerant bacteria

\section{Introduction}

The sequencing and annotation of the Pseudomonas putida KT2440 genome (Nelson et al. 2002) has greatly catalyzed research on this strain and other academically and biotechnologically relevant but non-sequenced $P$. putida strains. A number of key scientific advances (both pure and applied) have been made via proteome and transcriptome analysis of $P$. putida strains (Dominguez-Cuevas et al. 2006; Hallsworth et al. 2003; Morales et al. 2006; Reva et al. 2006; Santos et al. 2004; Segura et al. 2005; 
Volkers et al. 2006; Yuste et al. 2006). In our laboratories, we have studied both $P$. putida KT2440 (for recent publications: Hallsworth et al. 2003; Martins dos Santos et al. 2004; Nelson et al. 2002; Timmis 2002) and the solvent-tolerant P. putida S12 (De Bont 1998; Hartmans et al. 1990; Wery and De Bont 2004). Unlike most pseudomonads, solvent-tolerant strains possess an extraordinary tolerance to a broad variety of toxic solvents (for reviews: De Bont 1998; Kieboom and De Bont 2000; Ramos et al. 2002). A large number of high-added value bioconversions involve toxic, generally apolar, products (aromatics, aliphatic alcohols, epoxides, etc.). Especially for bioprocesses involving such products, the use of solvent-tolerant $P$. putida strains renders advantages in terms of productivity and the application of multiphase media for product recovery (Ramos-Gonzalez et al. 2003; Rojas et al. 2004; Wery and De Bont 2004; Wery et al. 2000; Wierckx et al. 2005). Despite their biotechnological potential, the genomes of S12 and other Pseudomonas strains have not been sequenced. So, recent studies of their metabolic potential have been limited to comparative proteomics (Segura et al. 2005; Volkers et al. 2006) or transcriptomics based on the database information for P. putida KT2440.

The genus Pseudomonas is very heterogeneous (Anzai et al. 2000); even strains of one species tend to vary greatly in terms of both phenotypic (Grimont et al. 1996) and genotypic characteristics (Brosch et al. 1996). Strains belonging to the species $P$. putida can be categorized into biovar A and B: the former grouping (A) is the more heterogeneous (Brosch et al. 1996) and the phylogenetic and metabolic diversity of biovar A strains has yet to be fully characterized and industrially exploited.

Comparative transcriptomics-based approaches have played a pivotal role in recent investigations of complex cellular responses of $P$. putida strains (Dominguez-Cuevas et al. 2006; Duque et al. 2007; Yuste et al. 2006). As transcriptome profiling is based on the highly-sensitive detection of DNA-cDNA hybridization, DNA sequence similarity determines the validity of these analyses. The inherent heterogeneity of the $P$. putida grouping provides additional cause for concern that microarray platforms derived from strain KT2440 may provide a valid framework for the study of nonsequenced P. putida strains.

We therefore carried out this study to assess the utility of KT2440-based high-density DNA microarrays for transcriptomics studies of DSM 6125 (subculture of KT2440), DSM

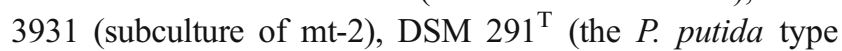
strain), the solvent-tolerant S12, and other nonsequenced Pseudomonas strains. In addition, the use of such microarrays to establish highly discriminative phylogenetic relationships between these strains was demonstrated.

\section{Materials and methods}

Strains, cultivation conditions, and DNA extraction

Single colonies from each Pseudomonas strain studied (see Table 1) grown on Pseudomonas Isolation Agar (Difco) were used to inoculate Luria-Bertani broth (LB) (Sambrook et al. 1982) in duplicate. After cultures were grown overnight at $30^{\circ} \mathrm{C}$, genomic DNAs were prepared from $5 \mathrm{ml}$ of culture (approximately $3 \times 10^{8}$ cells $/ \mathrm{ml}$ ) using the Genomic DNA $100 /$ G Kit (Qiagen, Germany) according to the manufacturer's instructions. DNA concentrations were determined at $260 \mathrm{~nm}$ using ND-1000 spectrophotometer (NanoDrop, Wilmington, DE, USA), and purity was confirmed by agarose $(1 \% \mathrm{w} / \mathrm{v})$ gel electrophoresis.

Table 1 Source and designations of Pseudomonas strains used in this study

\begin{tabular}{|c|c|c|}
\hline Species and strain number ${ }^{\mathrm{a}}$ & Source or reference ${ }^{b}$ & Other designations ${ }^{c}$ \\
\hline P. putida DSM 6125 & DSMZ & KT2440, ATCC 47054; NCIMB 11950 \\
\hline P. putida DSM 3931 & DSMZ & mt-2, ATCC 23973; ATCC 33015; JCM 6156; NCIMB 12182 \\
\hline P. putida $\mathrm{S} 12$ & Hartmans et al. 1990 & ATCC 700801 \\
\hline P. putida DSM $291^{\mathrm{T}}$ & DSMZ & DSM $50202^{\mathrm{T}}$; ATCC $12633^{\mathrm{T}}$; ICPB $2963^{\mathrm{T}}$; NCTC $10936^{\mathrm{T}}$; CCUG $12690^{\mathrm{T}}$; LMG $2257^{\mathrm{T}}$ \\
\hline P. putida DSM 50198 & DSMZ & ATCC 17453; ICPB 2563-77; JCM 6157; NCIMB 10007 \\
\hline P. putida DSM 50208 & DSMZ & ATCC 17485; ICPB 2789-111; JCM 6158; NCIMB 12092 \\
\hline P. monteilii DSM 14164 & DSMZ & ATCC 700476; CCUG 38736; LMG 21609; CIP 104883 \\
\hline P. fluorescens DSM $50090^{\mathrm{T}}$ & DSMZ & ATCC $13525^{\mathrm{T}}$; ICPB $3200^{\mathrm{T}}$; NCIMB $9046^{\mathrm{T}}$; NCTC $10038^{\mathrm{T}}$; CCUG $1253^{\mathrm{T}}$; LMG $1794^{\mathrm{T}}$ \\
\hline
\end{tabular}

${ }^{\text {a }}$ Strain designations used in this study

${ }^{\mathrm{b}}$ DSMZ Deutsche Sammlung von Mikroorganismen und Zellkulturen, Germany

${ }^{\mathrm{c}}$ Subcultures of the used strains available in other culture collections. ATCC American Type Culture Collection, ICPB International Collection of Phytopathogenic Bacteria, USA, NCIMB National Collections of Industrial and Marine Bacteria, UK, NCTC National Collection of Type Cultures, UK, JCM Japan Collection of Microorganisms, Japan, CIP Collection bacteriènne de l'Institut Pasteur, France, CCUG Culture Collection University Göteborg, Sweden, $L M G$ BCCM/LMG Bacteria Collection, Belgium. 
Preparation of biotin-labelled fragmented genomic DNAs

Approximately $17 \mu \mathrm{g}$ of heat-denatured genomic DNA was fragmented using $0.3 \mathrm{U}$ DNaseI (Pharmacia)/ $/ \mathrm{gg}$ DNA at $37^{\circ} \mathrm{C}$ for $20 \mathrm{~min}$ (Wolfgang et al. 2003). DNaseI was inactivated by immediate heat treatment at $95^{\circ} \mathrm{C}$ for $10 \mathrm{~min}$, followed by cooling on ice. An aliquot of fragmented DNA was analyzed by agarose $(4 \% \mathrm{w} / \mathrm{v}$ in TAE buffer) gel electrophoresis to confirm the purity and establish the mean size of DNA fragments (20-50 bp). Approximately $7 \mu \mathrm{g}$ of fragmented DNA was labelled with biotin according to the Affymetrix "Expression Analysis Technical Manual for Prokaryotic Samples”.

Design of high-density oligonucleotide microarrays and hybridization with genomic DNAs

High-density oligonucleotide microarrays based on the annotated genome of $P$. putida KT2440 (NC 002947.3) were constructed according to Affymetrix specifications (http:// www.affymetrix.com/support/technical/other/custom_design manual. pdf ) with the pair-wise configuration of 13 perfect match (PM) and mismatch (MM) 25-mer oligonucleotides per gene (probe set). The microarrays included 7,781 probe sets: 5,338 representing 5,350 annotated genes or open reading frames (orfs), and 2,443 targeting intergenic regions. Hybridization and washing of the microarrays were performed on a GeneChip ${ }^{\circledR}$ Node system (Hybridization temperature $49^{\circ} \mathrm{C}$; Hybridization oven 640 , Fluidics station 450; Affymetrix, Santa Clara, CA, USA) following the supplier's instructions. Scanning was carried out by ServiceXS (Leiden, The Netherlands) on a high resolution Gene Chip $^{\circledR}$ Scanner $30007 \mathrm{G}$ system with autoloader (Affyme- trix, Santa Clara, CA, USA) using the default analysis settings of the manufacturer (filter: $570 \mathrm{~nm}$; pixel size: $2.5 \mu \mathrm{m})$. Hybridization intensity data were extracted from the scanned array images, and the designations for presence or absence were calculated with Affymetrix Microarray Suite (MAS) 5.0 software. A one-sided Wilcoxon's Signed Rank was used to calculate $p$-values reflecting the statistical significance of differences between PM and MM of a probe set. The significance levels for detection calls of probe sets were $p$-value $<0.05$ for present and $p$-value $\geq 0.05$ for absent. Differences between PM and MM were considered insignificant and removed from further consideration by comparisons of the discrimination score $[(\mathrm{PM}-\mathrm{MM}) /(\mathrm{PM}+\mathrm{MM})]$ with the defined discrimination threshold $\tau$ (discrimination score $<0.015$ ). Comparisons of present/absent designations for genes in the different strains were made with GeneSpring version 7.2 (Agilent). Replicate assays of biological duplicates were performed for $P$. putida DSM 6125 and S12. The deviation caused by present/absent designations of genes in only one of both replicates was $0.8 \%$ for DSM 6,125 and $4.2 \%$ for S12 regarding all probe sets for putative genes and intergenic regions (Table 2).

\section{Calculation of dendrograms}

Simple matching similarity matrix based on the present/ absent detection calls in microarray analysis of different pseudomonads ( $\mathrm{SM}=m / n ; m$, number of matching probe sets; $n$, total number probe sets), and the microarray genotyping dendrogram were calculated using UPGMA parameters (unweighted pair group method, arithmetic average) and agglomerative hierarchical clustering with XLSTAT version 7.5.3 (Addinsoft, Paris, France).

Table 2 Similarity indices based on designations of presence or absence (stated in brackets) from hybridization signals of genomic DNA fragments from different Pseudomonas members on P. putida KT2440-based microarrays ${ }^{\text {a }}$

\begin{tabular}{llll}
\hline Strain & Present (absent) in percent (\%) & & \\
\cline { 2 - 4 } & $\begin{array}{l}\text { Putative genes and intergenic } \\
\text { regions }(7,781 \text { probe sets) }\end{array}$ & Putative genes (5,338 probe sets) & $\begin{array}{l}\text { Putative genes with assigned } \\
\text { function (3,670 probe sets) }\end{array}$ \\
\hline P. putida DSM $6125^{\mathrm{b}}$ & $97.6(1.4)$ & $99.6(0.0)$ & $99.8(0.0)$ \\
P. putida DSM 3931 & $98.6(1.4)$ & $99.9(0.1)$ & $100.0(0.0)$ \\
P. putida S12 & $78.0(16.9)$ & $81.8(13.9)$ & $86.9(9.7)$ \\
P. putida DSM $291^{\mathrm{T}}$ & $60.5(39.5)$ & $64.2(35.8)$ & $69.3(30.7)$ \\
P. putida DSM 50198 & $56.2(43.8)$ & $60.7(39.3)$ & $66.5(33.5)$ \\
P. putida DSM 50208 & $58.8(41.2)$ & $62.6(37.4)$ & $67.8(32.2)$ \\
P. monteilii DSM 14164 & $57.7(42.3)$ & $61.7(38.3)$ & $66.8(33.2)$ \\
P. fluorescens DSM $50090^{\mathrm{T}}$ & $22.0(78.0)$ & $27.2(72.8)$ & $30.7(69.3)$ \\
\hline
\end{tabular}

${ }^{a}$ Present/absent designations (present: $p<0.05$; absent: $p \geq 0.05 ; \tau=0.015$ ) derived from a decision matrix in Affymetrix MAS 5.0

${ }^{\mathrm{b}}$ Replicate assays were performed for P. putida DSM 6125 and $\mathrm{S} 12$ and the values listed include only genes that were designated present or absent in both replicates. 


\section{AFLP analysis}

In this paper, we used amplified fragment length polymorphism (AFLP) (Janssen et al. 1996; Savelkoul et al. 1999; Vos et al. 1995) to analyze different strains of $P$. putida a P. monteilii and a Pseudomonas fluorescens. AFLP is based on selective amplification of restriction fragments from totally digested genomic DNA. AFLP fingerprints were performed by KeyGene (Wageningen, The Netherlands). Genomic DNA of the different pseudomonads was digested using restriction enzyme combination NlaIII (Westburg, Leusden, The Netherlands) and Csp6I (Fermentas, St. LeonRot, Germany) according to manufacturers instructions. Each restriction enzyme was combined with the ligation of specific linker oligonucleotide pairs (NlaIII: 5-GACGATGAGTCCTGAG-3/5-TGTACGCAGTCTAC-3; Csp6I: 5-GACGAT GAGTCCTGAG-3/5-TACTCAGGACTCAT-3). For each of these linker combinations, AFLP was performed using nine N/C AFLP primer combinations, which were selected using KT2440 genome sequence as reference and software package REcomb (Keygene) for prediction analysis. These primers were extended with a $3^{\prime}$ terminal dinucleotide $(+2)$ and the extensions were $\mathrm{CA} / \mathrm{AC}, \mathrm{CA} / \mathrm{CA}, \mathrm{CA} / \mathrm{CC}, \mathrm{CA} / \mathrm{GG}$, $\mathrm{CA} / \mathrm{TT}, \mathrm{CT} / \mathrm{TT}, \mathrm{CT} / \mathrm{CA}, \mathrm{CT} / \mathrm{CT}$, and CT/TC. For further detail, please refer to Van den Braak et al. (2004). PCRs were performed in the presence of radioactive nucleotides, and the amplimers obtained were separated on $50 \times 20 \mathrm{~cm}$ polyacrylamide slabgels. Using phosphor-imaging, the individual presence/absence in a total of 757 markers (DNA bands) per strain was analyzed.

The total marker score data table (presence/absence of individual DNA bands) was subjected to genetic distance analysis using simple matching similarity matrix $(\mathrm{SM}=m / n$; $m$, the number of matched scores; $n$ the total sample size), consisting of similarity indices for all combinations of AFLP-banding patterns. Simple matching coefficients were calculated using NTSYSpc-software version 2.2 (Exeter Software, Setauket, NY, USA). To visualize the relationship between the strains, a dendrogram was generated using Sequential Agglomerative Hierarchical Nested (SAHN) cluster analysis with the use of UPGMA parameters.

\section{Standard PCR and sequencing}

Diagnostic PCR of selected putative orfs (PP1265, PP5224) that were called absent in microarray analyses of $P$. putida DSM 3931 genomic DNA was performed using proofreading enzyme mixture High Fidelity PCR master (Roche Diagnostics, The Netherlands) and specific primers (PP1265: forward: 5'-CTGCTGCACCAGGCCTAT-3', reversed: 5'TTGGTCACATAGCCGTCAAC-3'; PP5224: forward: 5'CAACGGCTAAACCTTTGCAT - ${ }^{\prime}$, reversed: 5'-AGGATC GAGACCTTGCCTTC-3'). Yielded PCR-amplicons of expected sizes, 1,108 and 1,062 bp, respectively, were sent to Baseclear (Leiden, The Netherlands) for sequencing according to Sanger et al. (1977) using nested sequencing primers (PP1265: 5'-CCAGGCAATCCGTGTCAT-3'; PP5224: 5'GGTGTCCTGACCGTCAAGTT-3'), and the resulting sequences were used for sequence alignments.

\section{Biological function-derived phylogenetic analysis}

The concept of Clusters of Orthologous Genes (COG; see Tatusov et al. 1997, 2003) was used during analysis of the genomic content of nonsequenced Pseudomonas strains by linkage to primary biological function (Table 3). A COG consists of individual proteins or groups of paralogs from at least three lineages and thus corresponds to an ancient conserved domain (Tatusov et al. 1997, 2003). In the NCBI-COG database, 4,497 proteins of 5,350 putative orfs in P. putida KT2440 were identified as COGs and were arranged in functional categories (see http://www.ncbi.nlm. nih.gov/sutils/coxik.cgi?gi=266 ). Because of the limited number of COGs in the functional categories (A) RNA processing and modification, (B) chromatin structure/ dynamics, and (W) extracellular structures $(1,2$, and 3 , respectively), these COGs were collectively grouped together with general function prediction COGs (Category R) under the designation $\mathrm{R}^{\prime}$ (see Table 3).

\section{Results}

Genomic DNA hybridizations with P. putida KT2440based high-density DNA microarrays

Total genomic DNA from P. putida strains, and other nonsequenced Pseudomonas members (see Table 1), was hybridized to custom KT2440-based high-density oligonucleotide microarrays. Presence or absence designations for each probe set (designed for specific genes and intergenic regions) were calculated by the Affymetrix MAS 5.0 algorithm from the significant difference (see Materials and methods section) in hybridization intensities between the corresponding perfect match and mismatch oligonucleotides (Table 2). Absence designation is a synonym for the absence of significant signal values and stands for divergent DNA still coding a similar biological function or for the complete absence of the specific DNA. Replicate array hybridizations were performed for DSM 6125 DNA and S12 DNA only. For these DNAs the values given in Table 2 represent only probe sets designated present or absent in both replicates. As expected, the DSM 6125 DNA yielded an almost perfect score: $97.6 \%$ for probe sets corresponding to all genetic elements (including the intergenic regions) and $99.8 \%$ for probe sets designed for genes with an assigned function. 
Table 3 Primary functional designation ${ }^{\mathrm{a}}$ of genes identified in P. putida S12 genomic DNA

\begin{tabular}{|c|c|c|c|}
\hline $\operatorname{Code}^{\mathrm{b}}$ & Description & COGs in $\mathrm{KT} 2440^{\mathrm{c}}$ & COGs KT2440 in S12 \\
\hline F & Nucleotide transport and metabolism & 93 & $87(93.5 \%)$ \\
\hline $\mathrm{J}$ & Translation & 194 & $178(91.8 \%)$ \\
\hline $\mathrm{H}$ & Coenzyme transport and metabolism & 183 & $166(90.7 \%)$ \\
\hline $\mathrm{T}$ & Signal transduction mechanisms & 427 & $387(90.6 \%)$ \\
\hline I & Lipid transport and metabolism & 194 & $174(89.7 \%)$ \\
\hline $\mathrm{N}$ & Cell motility & 130 & $116(89.2 \%)$ \\
\hline $\mathrm{G}$ & Carbohydrate transport and metabolism & 264 & $232(87.9 \%)$ \\
\hline $\mathrm{P}$ & Inorganic ion transport and metabolism & 368 & $322(87.5 \%)$ \\
\hline $\mathrm{U}$ & Intracellular trafficking and secretion & 119 & $104(87.4 \%)$ \\
\hline $\mathrm{E}$ & Amino acid transport and metabolism & 630 & $550(87.3 \%)$ \\
\hline $\mathrm{O}$ & Posttranslational modification, protein turnover, chaperones & 194 & $169(87.1 \%)$ \\
\hline $\mathrm{C}$ & Energy production and conversion & 321 & $276(86.0 \%)$ \\
\hline Q & Secondary metabolites biosynthesis, transport and catabolism & 161 & $138(85.7 \%)$ \\
\hline $\mathrm{K}$ & Transcription & 499 & $426(85.4 \%)$ \\
\hline $\mathrm{V}$ & Defense mechanisms & 66 & $56(84.8 \%)$ \\
\hline $\mathrm{R}^{\prime}$ & General function prediction only & 733 & $620(84.6 \%)$ \\
\hline $\mathrm{S}$ & Function unknown & 442 & $365(82.6 \%)$ \\
\hline M & Cell membrane biogenesis & 288 & $227(78.8 \%)$ \\
\hline $\mathrm{D}$ & Cell cycle control & 56 & $41(73.2 \%)$ \\
\hline- & Not in COGs & 853 & $544(63.8 \%)$ \\
\hline $\mathrm{L}$ & Replication, recombination and repair & 269 & $158(58.7 \%)$ \\
\hline
\end{tabular}

${ }^{a}$ Based on the Clusters of Orthologous Groups (COG) system, also see Materials and methods section)

${ }^{\mathrm{b}}$ Codes of functional categories of $\mathrm{COG}$

${ }^{\mathrm{c}}$ Proteins, 4,497 of 5,350 putative orfs in P. putida KT2440 can be found in COG database (http://www.ncbi.nlm.nih.gov/ COG/)

Strain DSM 3931 (subculture of $P$. putida mt-2: Teruko, 2002 ) is a TOL plasmid (pWW0)-containing variant of DSM 6125 and was used as an additional control for the accuracy of the microarray experiments. As expected, both strains were virtually indistinguishable in the array hybridization study (Table 2). Nonetheless four orfs were indicated absent in DSM 3931. These orfs were found to be called absent in only one of the DSM 6125 replicates. We therefore used diagnostic PCR to investigate the presence of two of them (PP1265, PP5224) in DSM 3931; the other two appeared less important due to their limited size ( $\sim 90 \mathrm{bp})$. In both cases, PCR products of the expected sizes (1,108 and $1,062 \mathrm{bp}$ ) were obtained that, after sequencing, proved to be identical to the KT2440 homologs.

Apart from DSM 3931, the solvent-tolerant S12 showed the highest genomic similarity to KT2440. Nearly 3,188 of $3,670(86.9 \%)$ genes with assigned functions in the KT2440 genome were identified in the genomic DNA of S12 (Table 2). Approximately $71 \%$ of 1,668 (putative) genes without an assigned function, and $70 \%$ of the intergenic regions were found to be present in the S12 (data not shown).

\section{Microarray-based genomotyping}

A dendrogram was constructed (Fig. 1a) based on genomic similarity of all 7,781 genetic elements of KT2440 in the tested genomic DNAs except for the control strain DSM 3931
(Table 2). DSM 6125, DSM 3931 (not shown), and S12 clustered in a group separate from the other $P$. putida strains (Fig. 1a). The nonsequenced P. fluorescens (DSM 50090 ${ }^{\mathrm{T}}$ ), that was included as an out-group, did not cluster with any other strain. By contrast, Pseudomonas monteilii DSM 3931 that was included as a non-putida member clustered with other $P$. putida strains suggesting a closer relationship with the P. putida taxonomic grouping (Fig. 1). To assess the validity of these microarray-derived phylogenetic relationships, AFLP DNA fingerprinting was used to obtain an independent phylogenetic classification of strains (Janssen et al. 1996; Savelkoul et al. 1999; Vos et al. 1995). The phylogenetic tree constructed following AFLP analyses showed an identical pattern in terms of strain grouping. (Fig. 1b).

An inventory was made of genes encoding proteins belonging to COGs (Tatusov et al. 1997, 2003) that were identified in the different genomic DNAs (Fig. 2). Of 5,350 orfs in the KT2440 genomic DNA sequence, 4,497 encode proteins that have been categorized into classes of primary biological function based on the COG system (http://www. ncbi.nlm.nih.gov/ COG/). It was found that, after DSM 3931, P. putida S12 showed the highest present score in all functional classes (Fig. 2). The "present" designations for S12 genes encoding COG members ranged from 58.7 to $93.5 \%$, depending on their primary biological function (Table 3, Fig. 2). The unequal distribution of the present designations over the different functional classes was also 
Fig. 1 Genome similarity between different Pseudomonas strains. a High-density microarray genotyping tree based on absent/present designations generated by Affymetrix MAS 5.0 algorithm (Table 2) using simple matching similarity coefficient, UPGMA, and agglomerative hierarchical clustering. b AFLP-genotyping. Tree is based on the score of 757 AFLP markers using the simple matching similarity coefficient and Sahn cluster analysis
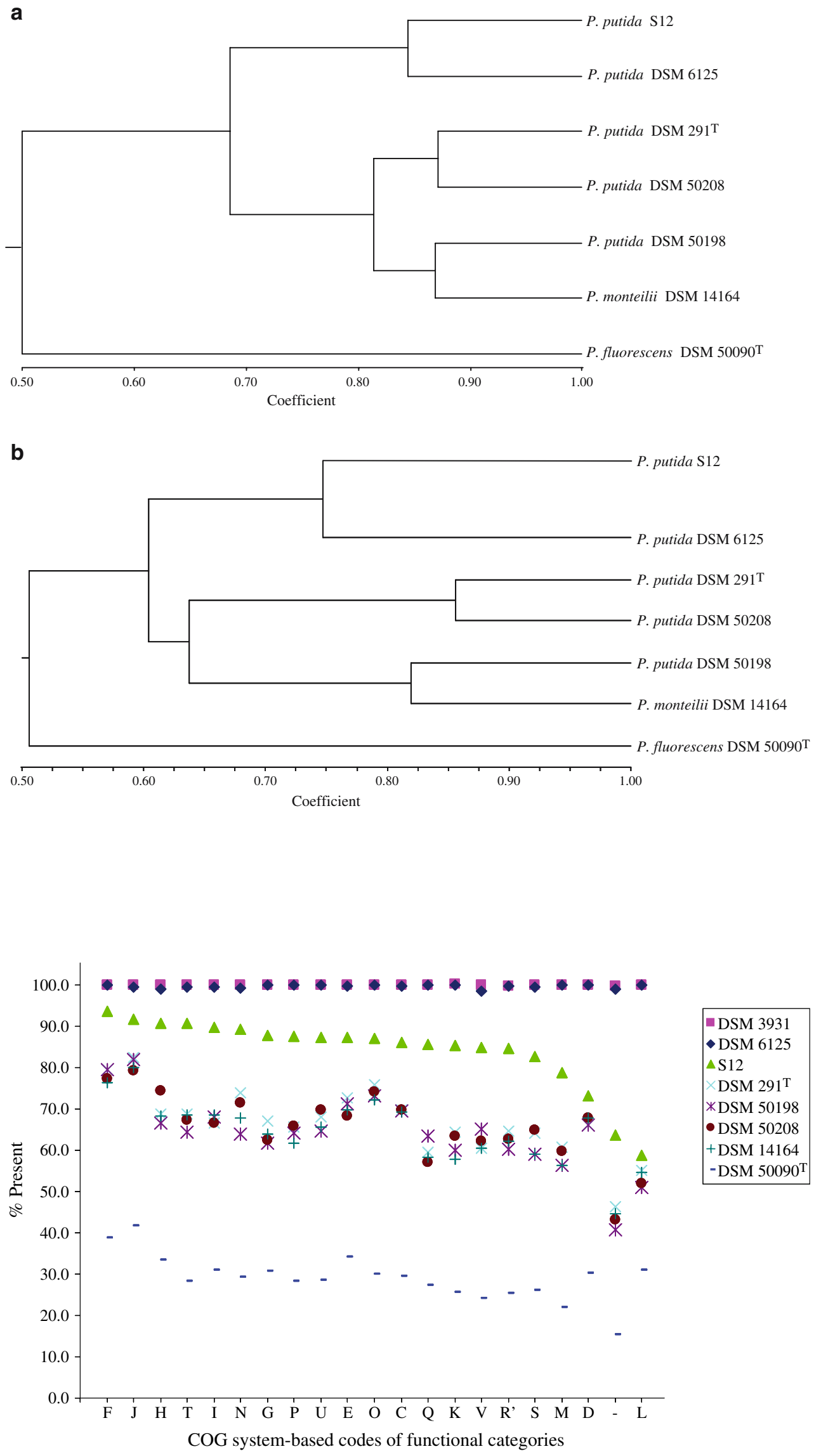
characteristic of other Pseudomonas strains (Fig. 2). Strikingly, all pseudomonads other than DSM 6125, DSM 3931, $\mathrm{S} 12$ and the out-group DSM50090 ${ }^{\mathrm{T}}$ showed a comparable distribution pattern of identified genes over the different COGs.

P. putida strains are well-known for their broad metabolic potential regarding aromatic compounds (Jimenez et al. 2002; Wackett 2003, for reviews). Several pseudomonads, including P. putida KT2440, have been reported to degrade and/or transform a variety of aromatics. Among these are compounds of industrial importance, and there is an interest in studying these metabolic pathways on the level of gene expression and regulation thereof. The utility of KT2440based microarrays in transcriptomics studies of aromatics metabolism of the pseudomonads under investigation was appraised. The presence of 70 genes of central and peripheral metabolic routes of aromatics were chosen based on reports by Jimenez et al. (2002) and Wackett (2003) (Table 4). All genes $(100 \%)$ were detected in DSM 6125, S12 and in DSM 3931. Higher divergence was found for P. putida DSM $291^{\mathrm{T}}$ (82.9\% detectable), DSM 50198 and DSM 50208 (both $75.7 \%$ detectable), and DSM 14164 (74.3\% detectable). DSM $50090^{\mathrm{T}}$ again behaved as an out-group with only $25.7 \%$ of the 70 genes detectable. In the P. putida strains used in the present study and DSM 14164, almost all genes for degradation of benzoate (ben), homogentisate ( $h m g$, mai), phenylalanine/tyrosine ( $p h h, t y r B$ ), and cat $A B$ were detected. In DSM 291, 50198, 50208 and 14164 putative regulatory genes of different pathways (e.g. catR, pcaQ, pobR, phaNM) and some isoenzymes (e.g., catA2) were not found (Table 4). Interestingly, in all these strains, the muconolactone isomerase ( $\mathrm{catC}$ ), and in the catabolism of phenylpropenoid compounds, vanillin dehydrogenase $(v d h)$, putative conifer aldehyde dehydrogenase (calB; except DSM 50198), and feruloyl-CoA synthetase ( $f c s$; except for DSM
50208) were not identified and can thus not be studied in KT2440-based microarray-based transcriptome analysis.

\section{Discussion}

A major advantage of microarray-based comparisons of species is the ability to pinpoint differences in individual genes and intergenic regions. Through these comparisons, detailed insight was gained in the utility of $P$. putida KT2440-based microarrays in transcriptomics studies of different pseudomonads at the level of specific categories of biological function. It was found that genes involved in, e.g., "translation" and "nucleotide transport and metabolism" could be identified at a high frequency $(>80 \%)$ in all $P$. putida strains tested, in contrast to other functional groups where the frequency of gene identification dropped below $60 \%$. Whereas $P$. fluorescens DSM $50090^{\mathrm{T}}$ behaved as a typical out-group in these functional studies, it was clear that, depending on the functional category, up to $45 \%$ of the genes of this strain could still be identified.

There is a biotechnological requirement for $P$. putida biocatalysts that can function at high solvent concentrations, such as strain S12, and that can be swiftly optimized for different bio-based production processes. In our group, studies have focused on the construction of strains that are able to convert renewable substrates, such as sugars, into aromatics of interest via central metabolites (Nijkamp et al. 2005, 2006; Wierckx et al. 2005). These conversions take place via multiple metabolic pathways each consisting of several enzymatic steps with regulatory mechanisms that are being investigated using $\mathrm{S} 12$ as a model system. A comparative transcriptomics approach is invaluable to gain detailed insights into the complex cellular systems of the metabolically versatile pseudomonads. The employment of

Table 4 Comparison of the presence/absence designations of genes encoding metabolic pathways of aromatic compounds in different pseudomonads derived from Affymetrix decision matrix MAS 5.0

Strain Present $(\%)^{\mathrm{a}} \quad$ Genes of aromatic pathways not identified in hybridizations with genomic DNA

P. putida DSM $6125 \quad 100.0$

P. putida DSM 3931

P. putida $\mathrm{S} 12$

P. putida DSM $291^{\mathrm{T}} \quad 82.9$

P. putida DSM $50198 \quad 75.7$

P. putida DSM $50208 \quad 75.7$

P. monteilii DSM 14164

P. fluorescens DSM 50090 ${ }^{\mathrm{T}} \quad 25.7$
catC; fadAxB2x; fcs; pcaQ; phaDHMN; vdh; calB; catA2

benE-1; catCR; ech; fadAxB2x; fcs; pcaDQ; phaGHMN; pobAR; vdh; catA2

catCR; ech; fadAxB2x; pcaBCQ; phaDHJMN; phhR; pobR; vdh; calB; catA2

benE-1; catCR; ech; fadB2x; fcs; pcaBDQ; phaEGHMN; pobAR; vdh; calB; catA2

aat; acdA; benACDE-1E-2FKR; catABCR; fadAxBB1xB2xDx; fcs; hpd; pcaCDHIJKQT; pcm; phaAB-EG-ILMN; phhBR; pobAR; tyrB-2; vanAB; vdh; calB; ferR; catA2

\footnotetext{
${ }^{a}$ Selected 70 genes $(100 \%)$ involved in catabolism of aromatic compounds annotated in P. putida DSM 6125: protocatechuate (pcaBCDFGHIJKQRT), catechol branches $\beta$-ketoadipate pathway (catABCRA2), homogentisate pathway ( $m g$ A, mai), central meta-cleavage (pcm), p-hydroxybenzoate (pobAR), benzoate (benABCDE-1E-2FKR), phenylacetate pathway (phaABCDEFGHIJKLMNJ1), n-phenylalkanoic acids (fadABDHAxB1xB2xD2Dx), phenylpropenoid compounds (vanAB, vdh, calB, ferR, fcs, ech, aat, acdA), and phenylalanine/tyrosine (phhABR, tyrB-1B-2, hpd, pcm).
} 
the high-density KT2440 microarrays would enable highly sensitive and reproducible transcriptome analyses that are compatible with those used for model species such as $P$. aeruginosa (Ochsner et al. 2002; Wagner et al. 2003; Whiteley et al. 2001) and Escherichia coli (Woo et al. 2004).

In the present study, we showed that the use of KT2440based microarrays would enable reliable transcriptomics analysis of $P$. putida S12. Significantly, we found that of all pseudomonads tested, the genomic content of P. putida $\mathrm{S} 12$ showed the highest similarity to that of $P$. putida DSM 6125 (KT2440). The vast majority of KT2440 genes coding for proteins involved in primary metabolism, including biosynthesis of important intermediates such as amino acids, and the genes involved in the conversion of aromatic compounds were shown to be sufficiently similar to those of S12.

The high resolution achieved by comparative genomotyping enabled the identification of minute genotypic differences between tested strains, making a meaningful analysis of phylogenetic relationships feasible. For example, the genomic DNA of $P$. putida DSM 6125 was shown to be virtually identical to that of the control strain DSM 3931, and this is consistent with the origin of strain KT2440 as a derivative of strain mt-2 (Regenhardt et al. 2002).

The relationship between the P. putida DSM $291^{\mathrm{T}}$ and KT2440 has been an issue of controversy. Based on $16 \mathrm{~S}$ rRNA gene comparisons (99\% identity), both strains appeared closely related; however, a DNA-DNA hybridization experiment indicated only $50.5 \%$ genome relatedness between both strains (Regenhardt et al. 2002). The results lead to doubts about the classification of both strains as part of the same Pseudomonas species, given the widely accepted recommendation that strains of the same species shall have genome similarities higher than $70 \%$ (Stackebrandt and Goebel 1994). In the same study, an appreciable distance between DSM $291^{\mathrm{T}}$ and KT2440 was established by REP-PCR genomic fingerprint patterns and Biolog GN metabolic profiling. In our genomotyping approach, $69.3 \%$ of the genes with an assigned function, $60.5 \%$ of all genetic elements (including intergenic regions), and $52.2 \%$ of the intergenic regions (not shown) were identified in the genomic DNA of $P$. putida DSM $291^{\mathrm{T}}$. These differences, which are supported by the AFLP analysis, indicate a considerable phylogenetic distance between DSM $291^{\mathrm{T}}$ and KT2440.

The diversity within the species $P$. putida was previously reflected in studies concerning genomic DNA ribotyping (Brosch et al. 1996), whole cell protein electrophoretic fingerprinting (Vacanneyt et al. 1996) and Biolog/Biotype100 experiments (Grimont et al. 1996). In our genomotyping studies, strains of $P$. monteilii and $P$. fluorescens were included as out-groups. P. fluorescens DSM $50090^{\mathrm{T}}$ was shown to be distantly related to the other Pseudomonas members tested, which supports its classification as a separate species. However, P. monteilii DSM 14164 clustered well with $P$. putida DSM 50198 and to a lesser extent with DSM $291^{\mathrm{T}}$ and $P$. putida DSM 50208. AFLP analysis showed a comparable result and confirmed the close relation between $P$. putida and $P$. monteilii. The present study thus suggests that DSM 14164 should more accurately be classified as a P. putida.

Other studies based on classification of $P$. monteilii by classical, well established taxonomic methods do not support our findings. DNA-DNA hybridizations among $P$. monteilii CFML $90-60^{\mathrm{T}}$, DSM $291^{\mathrm{T}}$, and DSM 50208 generated relative bindings of genomic DNA of 40 and $48 \%$, with $\Delta T_{\mathrm{m}}$ values of 9.2 and 7.9 , respectively (Elomari et al. 1997). Pyoverdine typing (siderotyping) analyzing the excreted siderophores during iron starvation of $P$. monteilii CFML $90-60^{\mathrm{T}}$ and DSM $291^{\mathrm{T}}$ produced different patterns for both strains (Dabboussi et al. 2002). Phenotypically, however, $P$. monteilii was previously shown to be highly similar to P. putida and could only be differentiated by assimilation experiments of the substrates inositol, $\alpha$-aminobutyrate, and $o$-/ $m$-hydroxybenzoate (Dabboussi et al. 2002; Elomari et al. 1997).

In conclusion, the genomotyping of different pseudomonads using KT2440-based DNA microarrays yielded novel insights in their phylogenetic relationships and the underlying identification of genes and their distribution over different primary and secondary biological functions. This revealed the utility of KT2440-based microarrays in transcriptomics and classification studies of these strains.

Acknowledgements This research was funded by the Kluyver Centre for Genomics of Industrial Fermentation, which is supported by the Netherlands Genomics Initiative (NGI) and by B-Basic, a public-private NWO-ACTS program. We acknowledge with special thanks the comments of Paul de Vos, University of Gent, for improving the taxonomic merits of the manuscript.

\section{References}

Anzai Y, Kim H, Park J-Y, Wakabayashi H, Oyaizu H (2000) Phylogenetic affiliation of the pseudomonads based on $16 \mathrm{~S}$ rRNA sequence. Int J Syst Evol Microbiol 50:1563-1589

Brosch R, Lefevre M, Grimont F, Grimont PAD (1996) Taxonomic diversity of pseudomonads revealed by computer interpretation of ribotyping data. Syst Appl Microbiol 19:541-555

Dabboussi F, Hamze M, Singer E, Geoffroy V, Meyer JM, Izard D (2002) Pseudomonas mosselii sp. nov., a novel species isolated from clinical specimens. Int J Syst Evol Microbiol 52:363-376

De Bont JAM (1998) Solvent-tolerant bacteria in biocatalysis. Trends Biotechnol 16:493-499

Dominguez-Cuevas P, Gonzalez-Pastor JE, Marques S, Ramos JL, de Lorenzo V (2006) Transcriptional tradeoff between metabolic and stress-response programs in Pseudomonas putida KT2440 cells exposed to toluene. J Biol Chem 281:11981-11991 
Duque E, Rodriguez-Herva JJ, de la Torre J, Dominguez-Cuevas P, Munoz-Rojas J, Ramos JL (2007) The RpoT regulon of Pseudomonas putida DOT-T1E and its role in stress endurance against solvents. J Bacteriol 189(1):207-219

Elomari M, Coroler L, Verhille S, Izard D, Leclerc H (1997) Pseudomonas monteilii sp. nov., isolated from clinical specimens. Int J Syst Bacteriol 47:846-852

Grimont PAD, Vancanneyt M, Lefevre M, Vandemeulebroecke K, Vauterin L, Brosch R, Kersters K, Grimont F (1996) Ability of Biolog and Biotype-100 systems to reveal the taxonomic diversity of the pseudomonads. System Appl Microbiol 19:510-527

Hallsworth JE, Heim S, Timmis KN (2003) Chaotropic solutes cause water stress in Pseudomonas putida. Environ Microbiol 5:1270 1280

Hartmans S, Van der Werf MJ, De Bont JAM (1990) Bacterial degradation of styrene involving a novel flavine adenine dinucleotide-dependent styrene monooxygenase. Appl Environ Microbiol 56:1347-1351

Janssen P, Coopman R, Huys G, Swings J, Bleeker M, Vos P, Zabeau M, Kersters K (1996) Evaluation of the DNA fingerprinting method AFLP as a new tool in bacterial taxonomy. Microbiology 142:1881-1893

Jimenez JI, Minambres B, Garcia JL, Diaz E (2002) Genomic analysis of the aromatic catabolic pathways from Pseudomonas putida KT2440. Environ Microbiol 4:824-841

Kieboom J, De Bont JAM (2000) Mechanisms of organic solvent tolerance in bacteria. In: Storz G, Hengge-Aronis R (eds) Bacterial stress responses. ASM press, Washington, pp 393-402

Martins dos Santos VAP, Heim S, Moore ERB, Strätz M, Timmis KN (2004) Insights into the genomic basis of niche specificity of Pseudomonas putida KT2440. Environ Microbiol 6:1264-1286

Morales G, Ugidos A, Rojo F (2006) Inactivation of the Pseudomonas putida cytochrome $o$ ubiquinol oxidase leads to a significant change in the transcriptome and to increased expression of the $\mathrm{CIO}$ and cbb3-1 terminal oxidases. Environ Microbiol 8:17641774

Nakazawa T (2002) Travels of a Pseudomonas, from Japan around the world. Environ Microbiol 4:782-786

Nelson KE, Paulsen IT, Weinel C, Dodson RJ, Hilbert H, Fouts DE, Gill SR, Pop M, Martins dos Santos VAP, Holmes M, Brinkac L, Beanan M, DeBoy RT, Daugherty S, Kolonay J, Madupu R, Nelson W, White O, Peterson J, Khouri H, Hance I, Chris Lee P, Holtzapple E, Scanlan D, Tran K, Moazzez A, Utterback T, Rizzo M, Lee K, Kosack D, Moestl D, Wedler H, Lauber J, Stjepandic D, Hoheisel J, Straetz M, Heim S, Kiewitz C, Eisen JA, Timmis KN, Dusterhoft A, Tümmler B, Fraser CM (2002) Complete genome sequence and comparative analysis of the metabolically versatile Pseudomonas putida KT2440. Environ Microbiol 4:799-808

Nijkamp K, Van Luijk N, De Bont JAM, Wery J (2005) The solventtolerant Pseudomonas putida S12 as host for the production of cinnamic acid from glucose. Appl Microbiol Biotechnol 69:170-177

Nijkamp K, Westerhof RGM, Ballerstedt H, de Bont JAM, Wery J (2006) Optimization of the solvent-tolerant Pseudomonas putida $\mathrm{S} 12$ as host for the production of $p$-coumarate from glucose Appl Microbiol Biotechnol DOI 10.1007/s00253-006-0703-0

Ochsner UA, Wilderman PJ, Vasil AI, Vasil ML (2002) GeneChip expression analysis of the iron starvation response in Pseudomonas aeruginosa: identification of novel pyoverdine biosynthesis genes. Mol Microbiol 45:1277-1287

Ramos-Gonzalez MI, Ben-Bassat A, Campos MJ, Ramos JL (2003) Genetic engineering of a highly solvent-tolerant Pseudomonas putida strain for biotransformation of toluene to $p$-hydroxybenzoate. Appl Environ Microbiol 69:5120-5127

Ramos JL, Duque E, Gallegos MT, Godoy P, Ramos-Gonzalez MI, Rojas A, Teran W, Segura A (2002) Mechanisms of solvent tolerance in gram-negative bacteria. Annu Rev Microbiol 56:7 43-768

Regenhardt D, Heuer H, Heim S, Fernandez DU, Strömpl C, Moore ERB, Timmis KN (2002) Pedigree and taxonomic credentials of Pseudomonas putida strain KT2440. Environ Microbiol 4:912-915

Reva ON, Weinel C, Weinel M, Bohm K, Stjepandic D, Hoheisel JD, Tümmler B (2006) Functional genomics of stress response in Pseudomonas putida KT2440. J Bacteriol 188:4079-4092

Rojas A, Duque E, Schmid A, Hurtado A, Ramos J-L, Segura A (2004) Biotransformation in double-phase systems: physiological responses of Pseudomonas putida DOT-T1E to a double phase made of aliphatic alcohols and biosynthesis of substituted catechols. Appl Environ Microbiol 70:3637-3643

Sambrook J, Fritsch EF, Maniatis T (1982). Molecular cloning: a laboratory manual. Cold Spring Harbour Laboratory Press, Cold Spring Harbor, NY

Sanger F, Nicklen S, Coulson AR (1977) DNA sequencing with chainterminating inhibitors. Proc Natl Acad Sci USA 74:5463-5467

Santos PM, Benndorf D, Sa-Correia I (2004) Insights into Pseudomonas putida KT2440 response to phenol-induced stress by quantitative proteomics. Proteomics 4:2640-2652

Savelkoul PHM, Aarts HJM, De Haas J, Dijkshoorn L, Duim B, Otsen M, Rademaker JLW, Schouls L, Lenstra JL (1999) Amplifiedfragment length polymorphism analysis: the state of the art. J Clin Microbiol 37:3083-3091

Segura A, Godoy P, Van Dillewijn P, Hurtado A, Arroyo N, Santacruz S, Ramos JL (2005) Proteomic analysis reveals the participation of energy- and stress-related proteins in the response of Pseudomonas putida DOT-T1E to toluene. J Bacteriol 187:5937-5945

Stackebrandt E, Goebel BM (1994) Taxonomic note: a place for DNA-DNA reassociation and 16S rRNA sequence analysis in the present species definition in bacteriology. Int J Syst Evol Microbiol 44:846-849

Tatusov RL, Koonin EV, Lipman DJ (1997) A genomic perspective on protein families. Science 278:631-637

Tatusov RL, Fedorova ND, Jackson JD, Jacobs AR, Kiryutin B, Koonin EV, Krylov DM, Mazumder R, Mekhedov SL, Nikolskaya AN, Rao BS, Smirnov S, Sverdlov AV, Vasudevan S, Wolf YI, Yin JJ, Natale DA (2003) The COG database: an updated version includes eukaryotes. BMC Bioinformatics 4:41-55

Timmis KN (2002) Pseudomonas putida: a cosmopolitan opportunist par excellence. Environ Microbiol 4:779-781

Vacanneyt M, Torck U, de Wettinck D, Vaerewijck M, Kersters K (1996) Grouping of pseudomonads by SDS-PAGE of whole-cell proteins. System Appl Microbiol 19:556-568

Van den Braak N, Simons G, Gorkink R, Reijans M, Eadie K, Kremers K, Van Soolingen D, Savelkoul P, Verbrugh H, Van Belkum, A (2004) A new high-throughput AFLP approach for identification of new genetic polymorphism in the genome of the clonal microorganismen Mycobacterium tuberculosis. J Microbiol Methods 56:4-62

Volkers RJM, De Jong AL, Hulst AG, Van Baar BLM, De Bont JAM, Wery J (2006) Chemostat-based proteomic analysis of tolueneaffected Pseudomonas putida S12. Environ Microbiol 8:16741679

Vos P, Hogers R, Bleeker M, Reijans M, Van de Lee T, Hornes M, Frijters A, Pot J, Peleman J, Kuiper J, Zabeau M (1995) AFLP: a new technique for DNA fingerprinting. Nucleic Acids Res 23:4407-4414

Wackett LP (2003) Pseudomonas putida - a versatile biocatalyst. Nat Biotechnol 21:136-138

Wagner VE, Bushnell D, Passador L, Brooks AI, Iglewski BH (2003) Microarray analysis of Pseudomonas aeruginosa quorum-sensing regulons: effects of growth phase and environment. J Bacteriol 185:2080-2095 
Wery J, De Bont JAM (2004) Solvent-tolerance of pseudomonads: a new degree of freedom in biocatalysis. In: Ramos JL (ed) Pseudomonas Vol 3: Biosynthesis of macromolecules and molecular metabolism, Kluwer Academic/Plenum Publishers, New York, pp 609-634

Wery J, Mendes da Silva DI, De Bont JAM (2000) A genetically modified solvent-tolerant bacterium for optimized production of a toxic fine chemical. Appl Microbiol Biotechnol 54:180-185

Whiteley M, Bangera MG, Baumgarner RE, Parsek MR, Teitzel GM, Lory S, Greenberg EP (2001) Gene expression in Pseudomonas aeruginosa biofilms. Nature 413:860-864

Wierckx JPN, Ballerstedt H, De Bont JAM, Wery J (2005) Bioproduction of phenol from glucose by Pseudomonas putida S12. Appl Environ Microbiol 71:8221-8227
Wolfgang MC, Lee VT, Gilmore ME, Lory S (2003) Coordinate regulation of bacterial virulence genes by a novel adenylate cyclase-dependent signaling pathway. Dev Cell 4:253-263

Woo Y, Affourtit J, Daigle S, Viale A, Johnson K, Naggert J, Churchill G (2004) A comparison of cDNA, oligonucleotide, and Affymetrix GeneChip gene expression microarray platforms. J Biomol Tech 15:276-284

Yuste L, Hervás AB, Canosa I, Tobes R, Jiménez JI, Nogales J, Pérez-Pérez MM, Santero E, E. D, Ramos J-L, De Lorenzo V, Rojo F (2006) Growth phase-dependent expression of the Pseudomonas putida KT2440 transcriptional machinery analysed with a genome-wide DNA microarray. Environ Microbiol $8: 165-177$ 